\title{
Integrated indicator to evaluate vehicle performance: safety, fuel efficiency and green domains
}

\author{
Torrao, G. ${ }^{a}{ }^{*}$, Fontes, ${ }^{\text {T. }}{ }^{b}$, Coelho, M. ${ }^{a}$ and Rouphail, N. ${ }^{c}$ \\ (a) University of Aveiro, Centre for Mechanical Technology and Automation / Dep. Mechanical \\ Engineering, Campus Universitário de Santiago, 3810-193 Aveiro, Portugal, \\ (b) Faculty of Engineering, University of Porto, Rua Roberto Frias, 4200-465, Porto, Portugal \\ (c) Civil \& Environmental Engineering Department and Institute for Transportation and \\ Research Education, North Carolina State University, Centennial Campus, 909 Capability Drive, Suite \\ 3600 Research Building IV, Raleigh, North Carolina 27606-3870, U.S.A. \\ (*) Corresponding author: University of Aveiro, Centre for Mechanical Technology and Automation / \\ Dep. Mechanical Engineering, Campus Universitário de Santiago, 3810-193 Aveiro - Portugal, Phone: \\ (+351) 234378 181,Fax: (+351) 234370 953, E-mail: quilhermina.torrao@ua.pt
}

\begin{abstract}
Usually, car manufacturers face trade-offs between safety, efficiency and environmental performance when choosing between mass, length, engine power, and fuel efficiency. However, based on the information provided to the consumers, is difficult to assess all these components. Thus, the main objective of this research was to develop an integrated tool able to evaluate simultaneously these domains in a simple way. Therefore, the SEG : Safety, Fuel Efficiency and Green Emissions evaluating vehicle's performance indicator was developed. For this purpose, crash data were collected in Porto (Portugal) for the period 2006-2010 ( $n=1374)$. Based on these data, crash severity prediction models were developed using advanced logistic regression models. Based on these results the SEG methodology was developed combining the vehicle's safety and the environmental evaluation into an integrated analysis. The results do not show any trade-off between vehicle's safety, fuel consumption and emissions. The best performance was achieved for newer gasoline passenger vehicles ( $<5 \mathrm{yr})$ with a smaller engine size $\left(<1400 \mathrm{~cm}^{3}\right)$. According with $S E G$, a vehicle with these characteristics can be recommended for a safety-conscious profile user, as well as for a user more interested in fuel economy and/or in green performance. On the other hand, for larger engine size vehicles $\left(>2000 \mathrm{~cm}^{3}\right)$ the combined score for safety user profile was in average more satisfactory than for vehicles in the smaller engine size group $\left(<1400 \mathrm{~cm}^{3}\right)$, which suggest that in general, larger vehicles may offer extra protection. The achieved results demonstrate that the developed methodology can be a helpful tool for consumers to evaluate their vehicle selection across different domains. Hence, this research is intended to support the decision-making process for transportation policy, safety and sustainable mobility, providing insights not only policy makers, but also for general public guidance.
\end{abstract}

Keywords: Integrated analysis; user profile; crash severity; vehicle performance 


\section{INTRODUCTION}

During the last decennia there has been an increase in the amount of consumer interest in the vehicle safety performance and fuel economy. Consumers tend to equate vehicle safety with the presence of specific features or technologies rather than with the outcomes of vehicle crash safety/test or crashworthiness [1]. Crash testing is a valuable source for consumer regarding vehicle crash safety and credits a car manufacturer for focusing on safety. Despite the scientific procedures under which crash tests are conducted, these tests have limitations. Under the EuroNCAP procedures tests, the frontal impact takes place at $64 \mathrm{~km} \cdot \mathrm{h}^{-1}$, meanwhile the car strikes deformable barrier that is offset [2]. It simulates one car having a frontal impact with another car of similar weight. Hence, it can only be compared with vehicles in the same class and within a $113 \mathrm{~kg}$ weight range [3]. Therefore, EuroNCAP discourage consumers from comparing ratings of cars from different segments, and in real crashes, there is obviously no control on the vehicle categories involved.

Chen and Ren [3] claimed that the relationship between vehicle safety ratings and fuel efficiencies seem to have been mostly positive correlated. Other work suggested that vehicle design, which can be improved by safety regulations, would be more effective on occupant safety than fuel economy standards that are structured to maintain vehicle size and weight [5]. On the other hand, other research stated that in vehicle design, there is a trade-off between fuel economy and secondary safety performance imposed by mass [6]. Even though mass imposes a trade-off in vehicle design, between safety and fuel use, it does not mean that it imposes a trade-off between safety and environmental goals in the vehicle fleet as a whole [6]. In other hand, other studies suggested that there is almost no tradeoff between better car safety and $\mathrm{CO}_{2}$ emission reduction [7]. The author claimed that enhanced safety of modern cars has a very small effect on vehicle mass and does not significantly affect fuel consumption [7].

While the advocates of the new vehicle standards claim for the benefits of energy and environment, opponents argue that vehicle safety will be compromised. The current structure of fuel economy standards could encourage manufacturers to sell more smaller, lighter cars to offset the fuel consumed by their bigger and heavier models [8]. "Automakers even are willing to sell smaller and less safe cars at a loss to ensure compliance with fleetwide requirements" [8]. A more recent study claimed that the two ways to decrease the $\mathrm{CO}_{2}$ emissions is decrease the mileage and the emissions per kilometer [9]. Other argued that the main way to reduce $\mathrm{CO}_{2}$ emissions is by reducing car weight, which means downsizing vehicles [8]. Nevertheless this research also suggests that would cause conflicts with occupants safety goals [8].The application of lightweight design with thermoplastics offers a possibility to reduce $\mathrm{CO}_{2}$ emissions and fuel consumption [10]. Substituting reinforced polymers in vehicle body components is a promising approach to weight reduction and fuel savings. Nanotechnology application into the automotive industry leads to lighter car bodies without compromising stiffness and crash resistance and results in less fuel consumption [11].

Thought automakers must comply with emissions regulations, consumers' preferences influence the market share by selecting vehicle attributes, such as car segment, fuel type, mass/size, and engine size. Until 2007, consumer's preferences shifts towards larger and less fuel-efficient car segments and also 
towards larger, heavier and more powerful cars within the same car segment [4]. From 2007 to 2011, consumer's preferences shift toward smaller car segments [4]. During the last years, due to fuel economy and $\mathrm{CO}_{2}$ emissions targets, and the global recession, manufacturers have increase the sales of smaller, lighter cars to offset the fuel economy by their bigger and heavier models. Smaller cars are more affordable, use less fuel and emit less pollutants.

The previous research work showed that the safety and environmental trade-offs are still not fully explained and they impose a challenge for the transportation and environmental authorities. The few existing studies in those trade-off analysis [3] [5][6][7], usually focus on the relationship between safety and fuel consumption, targeting $\mathrm{CO}_{2}$ emissions only, discarding local pollutants as carbon monoxide (CO), nitrogen oxide (NOx) and particle matter (PM) were not analyzed. Therefore, safety trade-offs are still a challenge and the following questions can be risen. Would a consumer have to choose the heaviest vehicle on the market to gain safety benefits? But if it does, other road users could be at higher risk specially the ones travelling in a lighter car. On the other hand, if all new passenger cars would shift towards larger and heavier vehicles, then what would be the cost in fuel consumption and emissions? Addressing these questions yield to the main motivation for this research. Thus, the major objectives of this work were:

1. Develop an integrated methodology to evaluate vehicle's safety, fuel efficiency and air emissions.

2. Provide an easier to use tool for consumer evaluation of vehicle performance based on user profile.

In order to address these questions, an integrated methodology was developed in this paper focusing the relationship between vehicle's safety and fuel consumption, considering not only $\mathrm{CO}_{2}$ emissions but also local pollutants as carbon monoxide (CO), nitrogen oxide $\left(\mathrm{NO}_{x}\right)$ and particle matter $(\mathrm{PM})$. Such methodology was conducted in two dimensions. Firstly, vehicle safety performance take into account its crashworthiness when involved in a single-vehicle crash and when involved in a twovehicle collision. Secondly, vehicle environmental performance covered not only vehicle $\mathrm{CO}_{2}$ emissions but also local pollutants (CO, NOx and PM), which are relevant in terms of air quality and has a high impact on human health in particular in urban areas [31].

This paper is organized as follows. Section 1 presents the previous work findings, highlights research gaps and presents the main objectives of this work. Section 2 presents the modeling framework and section 3 presents and discuss the results obtained for a scenario based analysis considering different user profiles. Last, section 4 provides the main conclusions.

\section{MATERIAL AND METHODS}

Figure 1 summarizes the main steps undertaken to execute an integrated methodology to assess vehicle safety, fuel efficiency and air emissions of a vehicle. First, crash data was collected and an extensive database was developed (see Section 2.1). Secondly, the effect of vehicle characteristics on its safety, fuel economy and air emissions were modeling (see Section 2.2). Lastly, the methodology used to 
develop an indicator to evaluate vehicle performance across those three domains was developed (see Section 2.3). Next sections describe each step.

FIGURE 1 Methodology overview.

\subsection{Data collection}

Data were collected in Oporto, one of the districts with higher crash severity rates in Portugal, 78 killed in 237,591 inhabitants during 2011 [12] [13]. For this study, crashes (single vehicle crashes and twovehicle collisions) involving light vehicles which have resulted in injuries and/or fatalities were selected. Recorded crash reports involving property damage only were excluded. Crash reports were gathered for 5-years' time period between 2006 and 2010.

For each crash observation collected from the road traffic Department of the Portuguese National Republican Guard (GNR), the information extracted from the police crash report was as follows: a) road name and location; b) weather conditions; c) driver's alcohol and/or drugs test results; d) crash type, vehicles' registration plate and registration year and e) crash outcomes, namely vehicle occupant's injuries and/or fatalities. Further, each vehicle's information in the crash dataset was recorded following the order stated in the Police crash report. The vehicle technical features were given by the Portuguese Institute for Mobility of Transports (IMT).

Based on these information's, a database was developed with a total of 1374 crash observations: 500 related to single-vehicle crashes and 874 related to two-vehicle collisions. In this sample 2248 light vehicles were analyzed. Table 1 shows the sample distribution vehicles by engine size, vehicle age and crash type.

\subsection{Modeling framework}

The modelling framework for vehicle's performance evaluation was done across three domains: safety, fuel consumption and emissions. Section 2.2.1 presents the development of models to predict the crash severity considering the vehicle characteristics while section 2.2.2 presents the environmental component including the energy efficiency evaluation and the emission evaluation of the vehicles that involved in a crash.

The safety and environmental modeling phases described next were performed using SAS $® v 9.2$ and SAS® Enterprise Miner ${ }^{\mathrm{TM}} 7.2$ software [14-16].

\subsubsection{Modeling the effect of vehicle characteristics in crash severity}

Vehicle safety was modeled for two different crash cases: single-vehicle crash and two-vehicle collisions. During the modeling phase the contribution of several vehicle related variables and crash information (e.g. legal speed limit, alcohol and/or drugs test results) where analyzed on its effect on 
crash severity. For single-vehicle crashes scenario, the vehicle was labelled as $V_{1}$. On the other hand, for two-vehicle collisions scenario, the safety analysis focused on the crash severity at vehicle designed as $V_{1}$ and also at the other vehicle involved, vehicle designed as $V_{2}$, as recorded within the police report records. Vehicle technical characteristics (e.g. weight (WT), engine size ( $c c$ ) and wheelbase (WB)) were analyzed for vehicle $V_{1}$, if a single-vehicle crash, and for vehicles $V_{1}$ and $V_{2}$, if a two-vehicle collisions had occurred. Table 2 identifies the independent variables that were analyzed to predict their impact on crash severity outcomes.

Based on the three levels of injury severity recorded by the Police Officers in Portugal, light injury (LI), serious injury (SI) and killed (K), a new dependent variable were defined: SIK, which represents the sum of the number of serious injured and killed in a crash. Using this dependent variable the probability of a serious injured and/or killed sustained by any occupant of a vehicle involved in a crash can be computed. Then, three binary targets were assigned and logistic regression models were applied to predict the binary response [17-20]. One target were design to analyze the crash severity when only one vehicle was involved and other two targets were design to analyze crash severity at each individual vehicle involved in a collision: Targets $P_{R_{S C, V}}, P_{R_{T C, V_{1}}}$ and $P_{R_{T C, V_{2}}}$, respectively, as shown in Table 2. As an example, $P_{R_{C R, V}}$ targets the prediction of the probability of a serious injured and/or killed sustained by the occupants of vehicle in a single-vehicle crash, and is assigned a value of " 1 " if $\mathrm{SIK}>0$, " 0 " otherwise.

Three logistic models were developed: one model to predict injury severity risk in single-vehicle crashes (Model IS, Equation 1), and two models to predict injury severity across the occupants of vehicles involved in collisions, one to predict the injury severity risk for $V_{1}$ 's occupants (Model IIS, Equation 2) and another to predict the injury severity risk for $V_{2}$ 's occupants (Model IIIS, Equation 3 ). The input variables used in these models are presented in Table 2.

$$
\begin{gathered}
P_{R_{S C, V}}=\frac{\exp \left(-3.4443+0.1572 * \mathrm{Age}_{V_{1}}+0.00139 * c c_{V_{1}}\right)}{1+\exp \left(-3.4443+0.1572 * A g e_{V_{1}}+0.00139 * c c_{V_{1}}\right)} \\
P_{R_{T C, V_{1}}}=\frac{\exp \left(-2.0657+0.00108 * c c_{V_{2}}\right)}{1+\exp \left(-2.0657+0.00108 * c c_{V_{2}}\right)} \\
P_{R_{T C, V_{2}}}=\frac{\exp \left(-3.5969+0.00205 * c c_{V_{1}}\right)}{1+\exp \left(-3.5969+0.00205 * c c_{V_{1}}\right)}
\end{gathered}
$$

Equation 1

Equation 3

Models assessment show that all the models performed well, reaching accuracy prediction rates of: $76 \%, 93 \%$ and $83.8 \%$, for $P_{R_{S C, V}}, P_{R_{T C, V_{1}}}$ and $P_{R_{T C, V_{2}}}$, respectively. For single vehicle crashes, the age of the vehicle and its engine size were statistically significant on risk prediction: $p$-value 0.0079 and $p$-value 0.0229 for $A g e_{V_{1}}$ and $c c_{V_{1}}$ respectively. For two-vehicle collisions, the engine size of the opponent vehicle was also statistically significant to estimate the risk at the subject vehicle: $p$-value 0.0762 and 0.0387 for $c c_{V_{1}}$ and $c c_{V_{2}}$, respectively. Fitting results and performance evaluation are summarized on Table 3. More details on the safety models development and assessment was published elsewhere [21].

In single-vehicle crashes (SC) (Model IS in Equation 1), the positive regression estimates shows a 
positive effect of vehicle engine size $\left(c c_{V_{1}}\right)$ and vehicle age $\left(A g e_{V_{1}}\right)$ on crash severity risk, $P_{R}=1$. Regarding to severity prediction for the two-vehicle collision (TC), Model IIS was developed to estimate the probability of a serious injured and/or killed in $V_{1}$ (expressed by $P_{R_{T C, V_{1}}}$. As the engine size of the opponent vehicle increase $\left(c c_{V_{2}}\right)$, the risk of $P_{R_{T C, V_{1}}}$ increases. On the other hand, for a subject vehicle being $V_{2}$, the Model IIIS also shows that the engine size of the opponent vehicle (labeled as $V_{1}$ ) increases the risk towards the occupants of the vehicle being analyzed, vehicle $V_{2}$ in this case.

\subsubsection{Modeling the effect of vehicle characteristics on environmental performance}

Regarding to the environmental domain, the effect of vehicle category, and technical characteristics on fuel consumption and local air pollutants emissions was analyzed. Thus, for the energy efficiency evaluation of the vehicles included in the crash database, carbon dioxide emissions $\left(\mathrm{CO}_{2}\right)$ were estimated to evaluate fuel consumption. For the air emissions vehicle green performance, carbon monoxide $(\mathrm{CO})$, nitrogen oxide $\left(\mathrm{NO}_{x}\right)$ and particle matter $(\mathrm{PM})$ were selected.

Despite of improvements due to catalytic converters, gasoline engines have been associated with higher $\mathrm{CO}$ emissions. On the other hand, diesel engines have been associated with significant emissions rates for $\mathrm{NO}_{x}$ and $\mathrm{PM}$ than gasoline engines [22, 23]. Thus, vehicles in the crash database were segregated by vehicle category. For light passenger gasoline vehicles (LPGV), CO emissions were evaluated, whereas for light passenger diesel vehicles (LPDV), $\mathrm{NO}_{x}$ and PM emissions were evaluated. On the other hand, $\mathrm{CO}_{2}$ emissions were evaluated for both gasoline and diesel vehicles, LPGV and LPDV, in order to address fuel consumption for all those categories.

To perform these emission estimation, the EMEP/EEA methodology was applied [24]. In this estimation several vehicle characteristics were taken into account, namely the vehicle fuel type (gasoline and diesel), engine size category and vehicle technology level. Since the vehicle travelling speed and driving share were unknown from the police records, emissions factors were calculated assuming that the vehicle average speed during the occurrence of the crash is approximately equal to the legal speed limit of the road where the crash happened. Thus the analysis was performed for $120 \mathrm{~km} \cdot \mathrm{h}^{-1}, 100 \mathrm{~km} \cdot \mathrm{h}^{-1} ; 90$ $\mathrm{km} \cdot \mathrm{h}^{-1}$, and $50 \mathrm{~km} \cdot \mathrm{h}^{-1}$ for motorways, complementary routes, rural roads and urban roads, respectively.

\subsection{Integrated methodology implementation}

In order to develop an integrated method to assess the vehicle performance across each domain by considering, simultaneously, safety, fuel efficiency and air emissions, the $S E G$ rates was developed. Next sections present such methodology considering two steps. First, section 2.3.1 presents the safety analysis mainly comprises the vehicle's risk of exposure and the injury severity risk prediction to estimate the overall safety score using the models presented on section 2.2.1.Then, section 2.3.2 describes the vehicles' fuel efficiency and emissions analysis involving the estimation of selected pollutants and its evaluation rating based on the models presented on section 2.2.2. 


\subsubsection{Methodology for vehicle safety rating}

To estimate the safety rating of a vehicle's crashworthiness (capability to protect vehicle's occupants) on a qualitative score the overall safety score $(O S S)$ was used. Such score is the product of the probability of exposure $\left(P_{D}\right)$ that a certain vehicle would be involved in a crash (based on the sample vehicles category distribution in Table 1 ) and the probability of crash injury severity risk $\left(P_{R}\right)$ (Equation 4). Probability of injury severity risk was estimated by applying the crash severity prediction models presented in section 2.2.1. Each term of the equation takes into account the vehicle's engine size ( $c c$ ) and vehicle's age ( $\mathrm{Age}$ ) categories and the number of vehicles involved (single-vehicle crash (SC) and two-vehicle collisions (TC)). Thus, OSS can be estimated as following:

$$
\text { OSS }=\left(P_{D_{V}} P_{R_{V}}\right)_{S C}+\left[\sum_{c c=1}^{c c}\left(P_{D_{V_{1}}} P_{D_{V_{2}}} P_{R_{V_{1}}, c V_{V_{2}}}\right)+\sum_{n=1}^{c c}\left(P_{D_{V_{2}}} P_{D_{V_{1}}} P_{R_{V_{2}}, c V_{V_{1}}}\right)\right]_{T C} \quad \text { Equation } 4
$$

In order to obtain a qualitative score, the obtained OSS values were converted into a qualitative score defined as: good, if $O S S$ is lower than a minimum (1.99\%), moderate if OSS is lower than a medium $(2.75 \%)$ and poor if $O S S$ is higher or equal to a maximum (2.75\%), as exhibited in Table 4 . The criteria to differentiate between good and moderate and moderate and poor safety ratings were established based on the maximum and minimum values of OSS using the training data scenario based on the crash sample, $[0.887 \% ; 3.915 \%]$. The lowest value, $0.887 \%$, is associated to the vehicle with best safety performance, on the other hand, the highest value, $3.915 \%$, is associated with the poorest safety performance for the vehicles tested with the scenario based analysis. Hence, based on the OSS range scale, the value of $1.99 \%$ was selected as cut off point for vehicle differentiation between good and moderate safety ratings, and the value of $2.75 \%$ was selected as cut point for vehicle differentiation between moderate and poor safety ratings.

\subsubsection{Vehicle's fuel efficiency rating}

Fuel efficiency rating was defined based on $\mathrm{CO}_{2}$ emissions, since they are a direct function of vehicles fuel consumption [24, 25]. For LPGV and LPDV these $\mathrm{CO}_{2}$ emissions were estimated using the corresponding model, as presented in section 2.2.2.

The criteria to assess vehicles $\mathrm{CO}_{2}$ emissions were established based on a recent study conducted by Kok (2013) who has published $\mathrm{CO}_{2}$ emissions by vehicle class and fuel type [4]. According this study, the average $\mathrm{CO}_{2}$ emissions for gasoline vehicles in the European fleet from 2000 to 2004 was 177 g.km-1. Since older vehicle models emitted more $\mathrm{CO}_{2}$, the value of $177 \mathrm{~g} \cdot \mathrm{km}^{-1}$ was used to set the criteria for the lowest and middle scores for fuel efficiency differentiation of LPGV. On the other hand, advanced efficiency technology in newer vehicles models is known to reduce $\mathrm{CO}_{2}$ emissions and fuel use. From 2005 to 2010 the average $\mathrm{CO}_{2}$ emissions for the European gasoline fleet was $158 \mathrm{~g} \cdot \mathrm{km}^{-1}$ and this value was used to set the criteria for the lowest and middle scores for fuel efficiency differentiation. For diesel vehicles (LPDV) the procedure was quite similar, although the average $\mathrm{CO}_{2}$ emissions values were calculated between 2000 and 2005 and between 2006 and 2010 to set the criteria for moderate and 
good fuel efficiency respectively. Table 4 show the efficiency rating criteria used for SEG integrated analysis.

\subsubsection{Vehicle's green emissions rating}

Vehicle green rating was based on the most relevant pollutants for each vehicle type, $\mathrm{CO}$ emissions for gasoline vehicles and $\mathrm{NO}_{x}$ and $\mathrm{PM}$ for diesel vehicles. For each category, air emissions $\left(\mathrm{g}^{\mathrm{k}} \mathrm{km}{ }^{-1}\right)$ were calculated using the methodology presented in section 2.2.2.

The green evaluation was based on the emission factors attributed to light passenger vehicles complying with Euro 2 and Euro 4 [24]. Euro 2 vehicles were equipped with three-way catalyst but they were not equipped with particle filters [24]. Thus, Euro 2 emission factors were chosen to differentiate between moderate and poor score emissions performance. On the other hand, Euro 4 vehicles benefit from advanced engine technology and improvements in the after treatment monitoring (for $\mathrm{NO}_{x}$ reduction and PM oxidation) and control [24]. Thus, Euro 4 emission factors were chosen to differentiate between good and moderate score. For the cases where two emissions scores are applied, the "lower" score was dominant when combined with a "higher" score. Thus, if a vehicle had good performance for one pollutant but moderate for the other, the final green score will be moderate. Table 4 presents the green rating criteria for each pollutant.

\subsubsection{SEG integrated framework}

$S E G$ rating leads to a qualitative classification of vehicle performance for each domain being analyzed: Safety $(S)$, Efficiency $(E)$ and Green $(G)$. The final output is a combined score which transforms vehicle rating into a quantitative score, designed as $S E G$ indicator. The final score assumes two principles:

1. On a descending order, the lowest value translates in the best vehicle performance, whereas the largest value relates to the poorest performance;

2. The combined score for a vehicle reaching the poorest rating for all the three domains will end up being one, assuming that the weighting factor attributed to each domain is the same.

$S E G$ indicator was calculated based on the sum of each domain's score times by the corresponding weight factor $(W F)$ divided by the sum of all the three weight factors. Equation 5 shows this calculation, where $S R$ is the safety rating, $E R$ is the efficiency rating and $G R$ is the green rating.

$$
S E G=\frac{S R * W F_{S}+E R * W F_{E}+G R * W F_{G}}{W F_{S}+W F_{E}+W F_{G}}
$$

Equation 5

The weighting factor attributed to each domain can be changed based on a user profile, as illustrated in Table 5. Thus, in order to assess the model, in this work four different scenarios were defined. Scenario $1\left(\mathrm{~S}_{\mathrm{N}}\right)$, defines a neutral user/consumer, which would tend to equate each evaluation domain with the same weight. Scenario 2, (Ss), is applied for a user interested in vehicle safety evaluation, whereas scenarios 3 and $4,\left(S_{E}\right.$ and $\left.S_{G}\right)$ are used to characterize users more concerned with fuel economy and air emissions impact, respectively. 
Finally, the qualitative rating of the integrated analysis: good, moderate and poor, is converted into numerical values: $0.1,0.5$ and 1 , respectively, in order to allow the calculation of the $S E G$ indicator score.

\section{RESULTS AND DISCUSSION}

SEG rating results are presented in a scenario based analysis derived by: vehicle category, fuel type, and flow traffic conditions. In this paper results are presented for LPGV and LPDV, for different vehicle ages (1-5 yr, 6-10 yr and 11-15 yr) and engine size $\left(<1400 \mathrm{~cm}^{3}, 1400 \leq c c<2000 \mathrm{~cm}^{3}\right.$, and $\left.>2000 \mathrm{~cm}^{3}\right)$ categories. Based on the levels of service standards (LOS) A through F from the Highway Capacity Manual [26], two typical speed profiles were assumed for the Portuguese motorways: $120 \mathrm{~km} \cdot \mathrm{h}^{-1}$ and $60 \mathrm{~km} \cdot \mathrm{h}^{-1}$, [26]. Whereas $120 \mathrm{~km} \cdot \mathrm{h}^{-1}$ would represent free flow conditions while $60 \mathrm{~km} \cdot \mathrm{h}^{-1}$ would represent unusual traffic conditions on motorway and/or when the driver is taking the off-ramp, where the maximum allowed speed is $60 \mathrm{~km} \cdot \mathrm{h}^{-1}$.

\subsection{SEG safety rating analysis}

The vehicle's safety performance analysis was developed in two steps: (i) first the risk of exposure and the probability of a severe crash outcome was discussed; and then (ii) the components score leading to OSS were analyzed. Table 6 presents this results considering several vehicle categories, vehicle age and engine size for vehicle involved in a single-vehicle crash and two-vehicle collision.

Firstly focusing on the first step, as an example, the analysis of the injury severity risk for a vehicle involved in a single-vehicle crash shows that the lowest probability of a severe crash outcome $\left(P_{R_{S C, V}}=\right.$ $0.2376)$ was associated to vehicles with the lowest engine $\left(\leq 1400 \mathrm{~cm}^{3}\right)$ and age $(<5 \mathrm{yr})$. On the other hand, the highest severity risk $\left(P_{R_{S C, V}}=0.8884\right)$, was associated with vehicles in the highest engines $\left(\geq 2000 \mathrm{~cm}^{3}\right.$ ) but with lower ages ( $<5 \mathrm{yr}$ ). These results can be explained by the fact that during the last years the auto industry has significantly improved not only vehicles' crashworthiness (secondary safety) but also active safety. Some of this technological developments involve the structure of the vehicles, with progressive crumple zones and more rigid survival cells, restrain systems (as pretensioning seat belts) and impact absorption systems (as airbags) [27]. On the other hand, larger engine size vehicles have been associated to more powerful vehicles which may potentiate speeding [6]. Therefore, singlevehicle crashes involving vehicles with larger engine sizes can increase the probability that its occupants would sustain severe injuries and/or fatalities. In addition, when involved in a collision, they impose more risk to the occupants of other vehicle involved. A similar analysis can be done for two-vehicle collisions.

Secondly focusing on the $O S S$, it takes into consideration the risk of exposure for the vehicle being analyzed in addition to the vehicle's predict injury severity risk involvement, discussed previously. The highest OSS (worst safety performance) was 4.0563 associated with vehicles with medium engine sizes $\left(1400 \leq c c<2000 \mathrm{~cm}^{3}\right)$ and age $(5-10 \mathrm{yr})$ categories. On the other hand, the best safety score $(O S S=0.9281)$ was associated with the newest vehicle categories (1-5 yr) and with a larger engine size 
$\left(>2000 \mathrm{~cm}^{3}\right)$. Thus, safety rating results based on OSS are affected not only by several vehicles characteristics, as proven by the severity risk prediction models, but also it is dependent on the risk of exposure, which is affected by the vehicle's age and engine size categories distribution in the crash sample, as exhibited in Table 1.

For middle engine sizes $\left(1400 \leq c c<2000 \mathrm{~cm}^{3}\right)$ and age $(6-10 \mathrm{yr})$ categories, the probability of injury severity risk for a vehicle involved in a single-vehicle crash was 0.554 (assuming an average value of $1700 \mathrm{~cm}^{3}$ and $8 \mathrm{yr}$ ). These vehicles categories represent the highest fraction of vehicle distribution at the crash sample, $15.7 \%$ (Table 1). Thus, for that reason, when the vehicle being analyzed falls in those categories, the risk of exposure is going to be higher, contributing to a higher safety score (i.e. poorest safety performance). On the other hand, for categories with high engine size ( $\left.\geq 2000 \mathrm{~cm}^{3}\right)$ and age (1-5 $\mathrm{yr})$, the probability of injury severity risk for a vehicle involved in a single-vehicle crash was higher $\left(P_{R_{S C, V}}=\right.$ 0.6230). Nonetheless, these vehicles categories are less representative at the crash sample, $4.0 \%$. Therefore, the risk of exposure is reduced, and hence OSS takes benefit of that. It is important to mention that, as more crashes would be added to the crash sample, the accuracy of the crash severity prediction models and the estimation of the risk of exposure would be improved.

\subsection{SEG environmental rating analysis}

The vehicle's environmental performance analysis was based on energy efficiency (fuel consumption) and air emissions estimation results. Table 7 presents the results for vehicles categories, engine size and vehicle age categories, assuming free flow $\left(120 \mathrm{~km} \cdot \mathrm{h}^{-1}\right)$ and congested scenarios on motorway (60 $\left.\mathrm{km} \cdot \mathrm{h}^{-1}\right)$.

Regarding to fuel efficiency based on $\mathrm{CO}_{2}$ estimations, vehicles in the $1-5 \mathrm{yr}$ age and $<1400 \mathrm{~cm}^{3}$ engine size categories showed the lowest $\mathrm{CO}_{2}$ emissions in free flow conditions $\left(120 \mathrm{~km} \cdot \mathrm{h}^{-1}\right), 165,984 \mathrm{~g} \cdot \mathrm{km}^{-1}$ and 163,722 g. km-1 for LPGV and LPDV, respectively, Table 7. Higher engine sizes have higher $\mathrm{CO}_{2}$ emissions. These results prove that newer vehicles models are more efficient and they use less fuel, especially the ones with smaller engine size. As can be observed in Table 7, fuel consumption and air emissions are clearly affected by the driving speed. For both vehicle categories, the analyzed fuel consumption was significantly lower, $13.9 \%$ for LPGV and $20.2 \%$ for LPDV, when the car circulate in reduced speeds $\left(60 \mathrm{~km} \cdot \mathrm{h}^{-1}\right)$ than when circulate in in free flow conditions $\left(120 \mathrm{~km} \cdot \mathrm{h}^{-1}\right)$.

Regarding to the environmental component the same pattern of $\mathrm{CO}_{2}$ is observed, namely regarding to travel speed and vehicle age. For instance, for gasoline vehicles, $\mathrm{CO}$ emissions increased as the age of the vehicle category increased and this increment was also observed as the engine size of the vehicle increased. Vehicles in the 1-5 $\mathrm{yr}$ age and $<1400 \mathrm{~cm}^{3}$ engine size categories showed the lowest CO emissions in free flow conditions $\left(120 \mathrm{~km} \cdot \mathrm{h}^{-1}\right), 1,515 \mathrm{~g} \cdot \mathrm{km}^{-1}$. For the same categories, CO emissions were significantly reduce $(73 \%)$ when the vehicles were evaluated under lower speeds scenario (120 $\left.\mathrm{km} \cdot \mathrm{h}^{-1}\right)$. 


\subsection{SEG integrated rating}

In this section the results of the integrated analysis of vehicle's performance evaluation across the three domains, safety, efficiency and green performance, are presented and discussed. First the results of the qualitative score is analyzed (see Section 3.3.1) and then the combined score, as SEG indicator is presented (see Section 3.3.2).

\subsubsection{SEG integrated qualitative rating}

Table 8 presents the results for vehicle evaluation, applying the $S E G$ qualitative score.

For gasoline vehicles at $120 \mathrm{~km} \cdot \mathrm{h}^{-1}$ driving scenario, vehicles in the older category, 11-15 yr with smaller engine size category $\left(<1400 \mathrm{~cm}^{3}\right)$ presented a $S E G$ integrated rating of poor, moderate and moderate for safety, efficiency and emissions, respectively. On the other hand, newer vehicles, 1-5 yr, with highest engine sizes ( $\left.\geq 2000 \mathrm{~cm}^{3}\right)$, have a $S E G$ rating classification of good, poor and poor, respectively. These $S E G$ rating results indicated that older vehicles with larger engine sizes achieved better safety performance than the ones in the smaller engine size category (good and poor, respectively). Larger engines size could be associated with larger cars, hence offering extra protection to its occupants. However, smaller engine size vehicles reveled better efficiency performance than larger engine size vehicles (moderate and poor, respectively). Larger engine size vehicles tend to be linked to larger mass than smaller engines, those contributing to extra fuel consumption. Newer vehicles models even though with smaller engine size, achieved good safety rating, suggesting improved occupant's protection during a crash. $S E G$ safety rating results support other research that concluding that drivers of recent cars are better protected than drivers of older vehicles [27-30]. Several emission-control systems improvements were introduced in the newer models to reduce $\mathrm{CO}$ emissions. Hence those have achieved moderate green performance whereas older ones showed poor or moderate performance. These findings are also consistent with previous research which show that during the last years, improvements in vehicles design and technology have contributed to improve green performance, allowing significant reductions in exhaust emissions $[3,7]$.

For diesel vehicles, the safety performance was the same as recorded for gasoline vehicles. This occur since injury severity prediction models did not select the variable fuel type. Regarding to efficiency and green performance, SEG rating showed a weak performance across all the three age and engine size categories. The green rating comprised both $\mathrm{NO}_{x}$ and PM emissions scores and the "lower" score of one of these pollutants was dominant to the other pollutant, as earlier explained in section 3.3.3. Anyway, under the $60 \mathrm{~km} \cdot \mathrm{h}^{-1}$ driving scenario, vehicles environmental performance achieved more satisfactory rating. For example, for a newer diesel vehicle (1-5 yr) with lower engine size $\left(<1400 \mathrm{~cm}^{3}\right)$ $S E G$ rating was: good, goof and good, to safety, efficiency and green performance respectively. The same good performance across the safety, efficiency and green domains was observed for newer gasoline vehicles (1-5 yr) with lower engine size $\left(<1400 \mathrm{~cm}^{3}\right)$. 
Table 9 presents the results for $S E G$ combined score by user profile. For this purpose, four users' profiles were defined to differentiate vehicle performance evaluation according to the user/consumer preference: neutral, safety, efficiency or ecology. As explained earlier, the best score, maximum vehicle performance, is attributed to vehicle's reaching 0.100 .

The results show that newer gasoline vehicles (1-5 yr - Euro 1) with smaller engine size $\left(<1400 \mathrm{~cm}^{3}\right)$ which are circulating at $120 \mathrm{~km} \cdot \mathrm{h}^{-1}$ have a $S E G$ combined score of 0.200 from the perspective of a safer user, $S_{s}\left(\right.$ Table 9). On the other hand, from the perspective of an efficient user $\left(\mathrm{S}_{E}\right)$ and/or an ecologist user $\left(\mathrm{S}_{\mathrm{G}}\right)$, the achieved combined score was 0.450 . Therefore, for a user to whom vehicle safety performance would be the most important, the above, category $\left(1-5 \mathrm{yr}\right.$ and $\left.<1400 \mathrm{~cm}^{3}\right)$ would be preferable.

For example, a safety-conscious consumer interested in a larger car for work proposed or family comfort, and who seeks for safety as a priority, vehicles younger than $5 \mathrm{yr}$ old and with large engine size, would be recommend, since it reached a $S E G$ combined score of 0.325 . However, for a user more interested in fuel consumption, efficiency-conscious user, this category would not be so appealing, reaching a SEG combined score of 0.888 , denoting poor efficiency.

For newer diesel vehicles (1-5 yr - Euro 4) with smaller or larger engine sizes which circulating at 120 $\mathrm{km} . \mathrm{h}^{-1}$, have $S E G$ combined score for a safer profile of 0.325 (Table 9). However from the respective of an efficient user and/or an ecologist user, this vehicle category could be dismissed, since $S E G$ combined score was 0.888 for both $\mathrm{S}_{\mathrm{E}}$ and $\mathrm{S}_{\mathrm{G}}$ (Table 9).

It must be clarify under the obtained results that, for both vehicles fuel type, gasoline and diesel, the category with larger engine size $\left(>2000 \mathrm{~cm}^{3}\right)$ also could be recommender for safety user, mainly the categories (1-5 yr and 11-15 yr) since both reached 0.325 for Ss. These result seem to suggest that larger vehicles may offer better protection to its accounts and its crashworthiness may be not so influence by vehicle model year as it is for smaller vehicles. Although it would be expected that older vehicles models safety protection systems could be less efficiency in protecting occupants, this category, (11-15 $\mathrm{yr}$ and $\left.>2000 \mathrm{~cm}^{3}\right)$ is less presentative in the crash sample (Table 1), and hence the risk of exposure would be smaller for those category, which could favor the OSS, despite of vehicle age.

Considering a lower speeds driving scenario, the most desirable vehicle performance across all users profiles was found for gasoline vehicles newer than $5 \mathrm{yr}$ old and with engine size smaller than $1400 \mathrm{~cm}^{3}$, which reached the maximum score of 0.1 for $S_{N}, S_{E}$ and $S_{G}$.

\section{CONCLUSIONS}

In this paper, an integrated methodology to evaluate vehicles in simultaneously across three major domains, safety, energy efficiency and green performance was developed. To develop this methodology, denominated as $S E G$, crash data recorded between 2006 and 2010 in the Oporto area (Portugal) were used to develop crash severity predictive models (logistic regression models), followed by emissions estimations for the vehicles in the crash data set using EMEP/EEA models. Then, crash 
severity prediction models and emissions estimation models were integrated into the $S E G$ indicator toll presented in this paper.

Based on the crash sample explored in this study, the best vehicle's performance was achieved by gasoline passenger vehicles in the categories, younger than $5 \mathrm{yr}$ and engine size smaller than 1400 $\mathrm{cm}^{3}$. For those vehicles when evaluated at $120 \mathrm{~km} . \mathrm{h}^{-1}$ driving scenario, SEG integrated rating was: good, moderate and moderate for safety, efficiency and green performance, respectively. The performance was even better when vehicles were evaluated at $60 \mathrm{~km} \cdot \mathrm{h}^{-1}$ driving scenario, achieving a good rating across the three domains. Thus, the $S E G$ integrated analysis results allow us to answer to the question earlier formulated: Is there a trade-off between vehicle's safety, efficiency and green performances? The results presented in this research reply a "No" to the previous question. Newer vehicles are safer, use less fuel and hence, fewer emissions, when compared with older vehicle models in the same weight range. $S E G$ safety results for vehicle in the newest age category (1-5 yr), showed a better overall safety rating compared with vehicle models of earlier year of manufacture.

An analysis by user profile, for a consumer more interested in vehicle safety evaluation, SEG combined score rating results revealed that gasoline vehicles in the larger engine size $\left(>2000 \mathrm{~cm}^{3}\right)$ achieved an average of 0.404 score across the three vehicle age groups analyzed, $(<5 \mathrm{yr}, 6-10 \mathrm{yr}$, and 11-15 yr), then vehicles with smaller engines $\left(<1400 \mathrm{~cm}^{3}\right)$, does showing poorest performance compared to the larger ones (score of 0.650 ). Similar trend was observed across diesel vehicles. These results seem to suggest that in general, larger vehicles may offer extra protection to its occupant's and they could be a safer selection across different vehicles age groups than smaller vehicles.

Advanced technology and improved vehicle design are very much reflected in $S E G$ ratings, and it is evident that newer vehicles achieve good performance on all three domains when not speeding. However, newer vehicles models, should not be downsized, but rather, take advantage of new technologies of mass reduction and materials, such as aluminum and high-strength steel, to be lighter and resistant, not smaller. Vehicle size matters in protecting vehicle occupants, but this should not impose a conflict with the goal of improved fuel efficiency and emissions control technologies. Decision making and setting agreements are required to make advanced technologies accessible to auto brands in order to improve the performance of car fleet. Thus, several main advantages vehicle's performance evaluation using $S E G$ indicator can be highlighted:

1. It is designed to be an easy-to-use tool to assist consumers in vehicle's selection based on users profile style: neutral, safety-conscious, efficient-conscious or eco-conscious;

2. It allows the evaluation of vehicle's safety performance for single-vehicle crashes and for twovehicle collisions, as well as the comparison between vehicles above a $113 \mathrm{~kg}$ weight range (overcame the limitations of the EuroNCAP rating among different vehicle weights);

3. It allows the evaluation of vehicle's efficiency and green performance ratings in a flexible scale for different scenarios and taking into account vehicles' engine size and age categories;

4. Overall safety rating takes into account the effect of vehicle characteristics in crashworthiness. In addition, it includes risk of exposure for the vehicle category being analyzed.

In this analysis, some limitations were found when evaluating some vehicles categories which are 
related for two main factors. First the use of an integrating EMEP/EEA emissions estimation methodology to set $S E G$ evaluation criteria introduce some limitations in the categories definition which is important to taken into account. In addition, the vehicles categories distribution at the data sample, which affects the risk of exposure also covered in the overall safety analysis and the emissions estimations models represents another limitation, since the model is very dependent of the sample distribution. Thus, is important to mention that, as more crashes would be added to the crash sample, the probability of crash severity and risk of exposure would become more stable and OSS would be more accurate. Rather than the obtained results expressed some limitations, SEG integrated methodology by itself is a promising tool that can be improved by having access to a larger crash sample for further application in real life vehicles evaluation and/or selection. As final remark, whereas the models presented in this paper are not able to be "copy" to other countries, as the vehicle fleet would be different, the integrated methodology framework could be used in other countries for vehicle's performance evaluation, overcoming some of the gaps currently identified.

\section{Acknowledgments}

This work was partially funded by FEDER Funds through the Operational Program "Factores de Competitividade - COMPETE" and by National Funds through FCT - Fundação para a Ciência e Tecnologia within the project PTDC/SEN-TRA/113499/2009, by the Strategic Project PEstC/EME/UI0481/2014, and FLAD - Luso American Foundation. G. A. Torrão also acknowledges the support of FCT for the Scholarship SFRH/BD/41350/2007. The collaboration between Drs. Coelho and Rouphail was under the auspices of the Luso-American Transportation Impacts Study Group (LATIS$\mathrm{G})$. Any opinions, findings, conclusions or recommendations expressed in this document are those of the author(s) and do not necessarily reflect the views of FCT, FLAD, or LATIS-G.

\section{References}

1. Koppel S, Charlton J, Fildes B, Fitzharris M. How important is vehicle safety in the new vehicle purchase process? Accident Analysis and Prevention. 2008;40(3):994-1004.

2. EuroNCAP. Euro NCAP. Frontal Impact 2011 [26 Oct., 2011]; Available from:

http://www.euroncap.com/tests/frontimpact.aspx.

3. Chen C, Ren Y. Exploring the relationship between vehicle safety and fuel efficiency in automotive design. Transportation Research Part D: Transport and Environment. 2010;15(2):112-116.

4. Kok R. New car preferences move away from greater size, weight and power: Impact of Dutch consumer choices on average CO2-emissions. Transportation Research Part D: Transport and Environment. 2013;21(0):53-61.

5. Wenzel T. Analysis of the Relationship Between Vehicle Weight/Size and Safety, and Implications for the Federal Fuel Economy Regulation. Final Report prepared for the Office of Energy Efficiency and Renewable Energy. In: Energy UDo, editor. US2010.

6. Tolouei R, Titheridge H. Vehicle mass as a determinant of fuel consumption and secondary safety performance. Transportation Research Part D: Transport and Environment. 2009;14(6):385-399.

7. Zachariadis T. The effect of improved safety on fuel economy of European cars. Transportation Research Part D: Transport and Environment. 2008;13(2):133-139.

8. IIHS. IIHS. Car size and weight are crucial. Statut Report 2009;44(4).

9. Bampatsou C, Zervas E. Critique of the regulatory limitations of exhaust $\mathrm{CO} 2$ emissions from passenger cars in European union. Energy Policy. 2011;39(12):7794-7802. 
10. Park HS, Dang XP, Roderburg A, Nau B. Development of plastic front side panels for green cars. CIRP Journal of Manufacturing Science and Technology. 2013;6(1):44-52.

11. Coelho M, Torrão G, Emani N, Grácio J. Nanotechnology in automotive industry: research strategy and trends for the future-small objects, big impacts. Journal of Nanoscience and Nanotechnology. 2012;12(8): 66216630 .

12. Authority NRS. Fatalities on the 30 days basis. Year 2013. Lisbon: National Road Safety Authority, 2014.

13. Institute PNS. Population by reagion. Porto Census for 2011. 2014; Available from:

http://www.ine.pt/bddXplorer/htdocs/widgetCensosGet.jsp.

14. Sarma KS. Predictive modeling with SAS Enterprise Miner: practical solutions for business applications. Cary, NC: SAS Institute; 2007.

15. SAS Institute Inc. S. Applied Analytics Using SAS®Enterprise MinerTM 5. Instructor-based training. Cary, NC, USA: SAS Institute Inc.; 2007.

16. SAS Institute Inc. S. Statistics I: Introduction to Anova, Regression, and Logistic Regression. Cary, NC, USA: SAS Institute Inc.; 2009.

17. Savolainen PT, Mannering FL, Lord D, Quddus MA. The statistical analysis of highway crash-injury severities: A review and assessment of methodological alternatives. Accident Analysis and Prevention. 2011;43(5):1666-1676.

18. Kononen DW, Flannagan CAC, Wang SC. Identification and validation of a logistic regression model for predicting serious injuries associated with motor vehicle crashes. Accident Analysis and Prevention. 2011;43(1):112-122.

19. Harrell J, Frank E. Regression Modeling Strategies With Applications to the Linear Models, Logistic Regression, and Survival Analysis. 2001 0-387-95232-2.

20. Ali S A-G. Using logistic regression to estimate the influence of accident factors on accident severity. Accident Analysis \&amp; Prevention. 2002;34(6):729-741.

21. Torrão G, Coelho M, Rouphail N. Modeling the impact of subject and opponet vehicle on crash severity in two-vehicle collisions Washington D.C., : 93rd Annual Meeting of the Transportation Research Board; 2014. 22. Franco V, Kousoulidou M, Muntean M, Ntziachristos L, Hausberger S, Dilara P. Road vehicle emission factors development: A review. Atmospheric Environment. 2013;70(0):84-97.

23. Kiely G. Environemental Engineering: McGFraw Hill; 1999.

24. EEA EEA. EMEP/EEA. European Monitoring and Evaluation Programme (EMEP). Emission

Inventory Guidebook - 2009: Exhaust emissions from road transport. European Environment Agency, 2013.

25. EC. Climate Action. Reducing CO2 emissions from passenger cars. European Comission. 2012 [23

April 2013]; Available from: http://ec.europa.eu/clima/policies/transport/vehicles/cars/index en.htm.

26. TRB. Highway Capacity Manual 2010. Transportation Research Board. edition t, editor: Transportation Research Board; 2010.

27. Martin JL, Lenguerrand E. A population based estimation of the driver protection provided by passenger cars: France 1996-2005. Accident Analysis and Prevention. 2008;40(6):1811-1821.

28. Broughton J. Car driver casualty rates in Great Britain by type of car. Accident Analysis and Prevention. 2008;40(4):1543-1552.

29. Méndez ÁG, Aparicio Izquierdo F, Ramírez BA. Evolution of the crashworthiness and aggressivity of the Spanish car fleet. Accident Analysis \&amp; Prevention. 2010;42(6):1621-1631.

30. Chen D, Kockelman K, editors. The role of vehicle footprint, height, and weight in crash coutcomes: application of a heteroscedastic ordered proibit model. 91st Annual Meeting of the Transportation Research Board; 2012; Washington, DC 20001 USA.

31. Barros N, Fontes T, Silva MP Manso MC. "How wide should be the adjacent area to an urban motorway to prevent potential health impacts from traffic emissions?", Transportation Research Part A: Policy and Practice 2013;50, 0:113-128. 